\title{
Additive manufacturing of self-compacting concrete through controlled heating
}

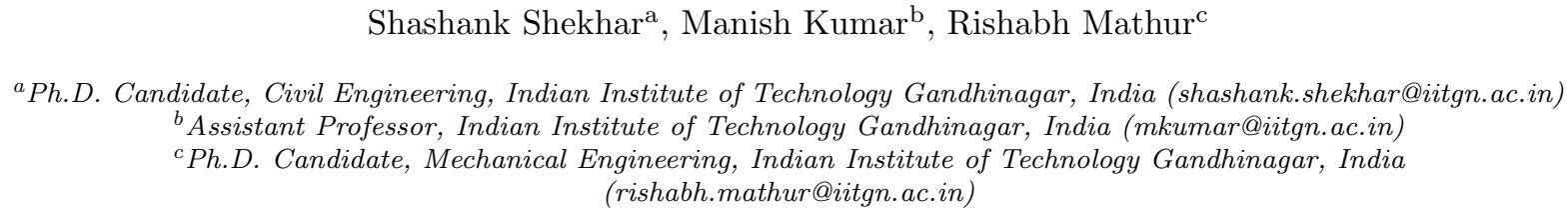

8 Abstract

Construction using concrete through additive manufacturing is gaining attention. This approach involves a layer-wise deposition of concrete. A layer of printed concrete needs to be "strong" enough to sustain the weight of layers to be printed above. These layers may not bond well with each other, however. Self-compacting concrete (SCC) may lead to a better bonding, but it may not have sufficient strength. This paper presents a method to print SCC through controlled heating. Properties of printed concrete in fresh and hardened states are studied. Heating leads to a sharp rise in the strength of freshly-printed concrete layers, but a long duration of heating may lead to a reduction in strength of printed concrete after hardening particularly if water-to-cement ratio is small or if loads are applied parallel to the printed layers.

Keywords: self-compacting concrete; additive manufacturing; 3D printing; heating; infrared reflectance; surface texture; buildability

\section{Introduction}

Conventional construction using concrete includes preparation of concrete mix, placement of the mix into the formwork, compaction, removal of the formwork after the concrete has gained sufficient strength, and curing. This process is labour-intensive, time-consuming, and the shape of a structural member is often limited by the available formwork. Additive manufacturing (also known as three-dimensional (3D) printing) of concrete can help overcome these challenges [1-7].

Fresh-state properties of cast-in-situ concrete are characterized in terms of setting time, workability etc. Similarly, strength and stiffness parameters are used to characterize the hardened concrete castin-situ. Parameters such as buildability, shape stability, extrudability, open time and surface moisture have been reported for freshly-printed concrete in the past $[8,9]$. Similarly, shrinkage and strength of printed concrete after hardening also have been reported [10]. A brief discussion on the properties of printed concrete is presented in the paragraphs below.

Buildability is an indicator of the strength of freshly-printed concrete. There is no widely accepted 
definition of buildability. Maximum number of free-standing layers (e.g., [8]), compressive strength of a freshly-printed specimen (e.g., $[9,11]$ ), ultrasonic pulse velocity through a freshly-printed specimen (e.g., [12]), and depth of penetration of Vicat plunger into freshly-printed concrete layers [13] have been considered as measures of the buildability in the past. A parameter related to buildability is shape stability, which refers to the similarity between the achieved and intended dimensions of a printed specimen. Ali Kazemian et al. [9] printed a filament of concrete through a $38.1 \mathrm{~mm} \times 25.4 \mathrm{~mm}$ nozzle, and the width of the printed filament ranged between $38.1 \mathrm{~mm}$ and $48 \mathrm{~mm}$. They considered a printed specimen to have "dimension consistency" if the dimensions of the printed line were within $10 \%$ of the dimensions of the nozzle. Rahul et al. [14] printed a filament of concrete through a nozzle of size $30 \mathrm{~mm}$ $\times 20 \mathrm{~mm}$, and considered a mix to be "extrudable" if dimensions of the cross-section of the printed filament was within $0.5 \mathrm{~mm}$ of the dimensions of the nozzle (approximately $2 \%$ of the dimension of the nozzle). Panda et al. [15] defined a "shape retention factor" as the ratio of cross-sectional area of the nozzle to that of the printed line, and observed that the factor for the printed specimens was between 0.7 and 0.9. Open time for printing a concrete mix is defined as the duration for which the mix can be extruded with a consistent rate without chocking the pump. Le et al. [8] have defined the open time as the duration in which the yield strength of the mix increases by $0.3 \mathrm{kPa}$ from its initial value. Surface moisture can be characterized as the mass of water extracted from the surface of printed layer through a paper cloth (e.g., [16]).

Strength of the printed specimens vary depending on whether the direction of loading is parallel or perpendicular to the printed layers $[10,17,18,18]$. A standard method to perform the tests (e.g., size of specimens) is yet to evolve. Drying shrinkage in printed concrete has been reported to be affected by curing conditions (e.g., [10]). Pore sizes ranging between $0.2 \mathrm{~mm}$ and $4 \mathrm{~mm}$ have been reported (e.g., [10]); also see Figure 1(b). Porosity of the printed concrete after hardening has also been reported [18].

A wide spectrum of concrete mixes have been printed in the past: high strength concrete (e.g., [10]), ultra-high strength concrete (e.g., [19]), fibre-reinforced concrete (e.g., [20, 21]), and geo-polymer concrete (e.g., $[22,23])$. Reported initial yield strength of the concrete printed till date has been in the range of $300-4,000 \mathrm{~Pa}[8,11,22,24-27]$. Rahul et al. [14] suggest that initial yield strength of the concrete mix for acceptable extrudability and buildability should be in the range of 1,500 - 2,500 Pa. Filaments of the printed concrete are "strong" as a consequence, and do not bond well with each other leaving considerable amount of voids after hardening [16, 18, 28, 29]. Panel (a) of Figure 1 presents the schematic of a section through "strong" filaments, and panel (b) shows a surface of the printed concrete with strong filaments cut after hardening [10]. A better bonding between filaments can be achieved using a self-compacting concrete (SCC); initial yield strength of SCC is less than $100 \mathrm{~Pa}$ (e.g., [30, 31]). A challenge in printing the SCC, however, is to ensure that a printed layer achieves the capacity to support 


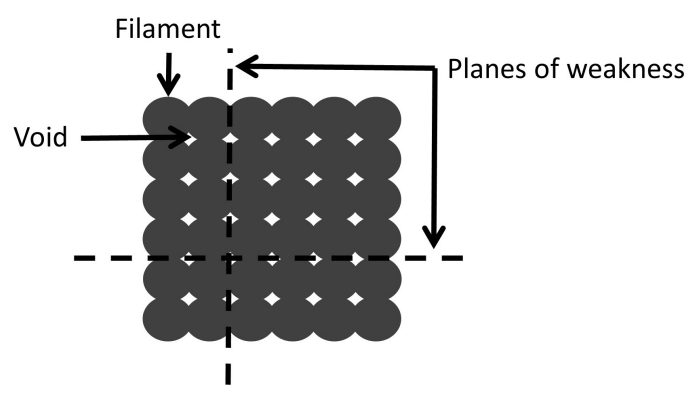

(a) Schematic of voids between filaments

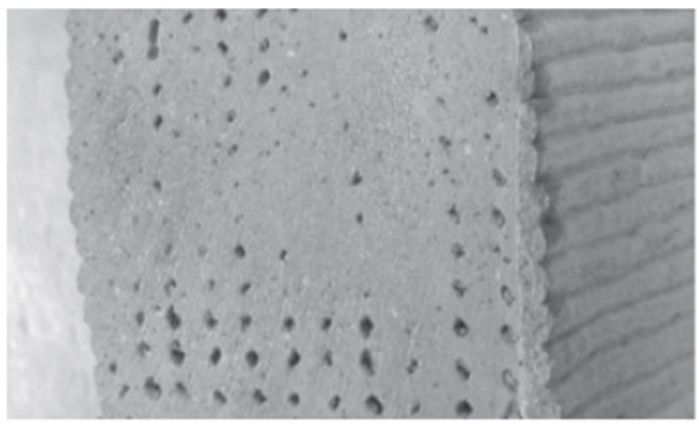

(b) Voids in printed concrete (adapted from [10])

Figure 1: Voids between filaments of printed concrete

the layers above in a reasonable time frame. The initial strength gain of the SCC can be accelerated using chemical admixtures (e.g., calcium sulpho-aluminate, calcium chloride, calcium aluminate and sodium sulphate $[9,13,21,32-39])$. However, the admixtures may cause choking in the printing set-up due to accelerated setting, lead to expansive hydration reaction [40], produce high heat of hydration [41], and/or have chemicals that can accelerate corrosion in reinforcement. These accelerators often need to be added to the mix near the nozzle (e.g., in shotcrete applications [32, 42, 43]), which complicates the design of the printing set-up.

This paper presents a method to print self-compacting concrete mixes through controlled heating. An in-house concrete printing set-up has been developed at Indian Institute of Technology (IIT) Gandhinagar, India. The set-up comprises of motion assembly, extrusion assembly, heating system, and infrared reflectance feedback system [44]. The motion assembly enables the horizontal and vertical motion of the printing platform. Self-compacting concrete is deposited on the printing platform through the extrusion assembly. Heating system removes a portion of the moisture from printed layer, which increases the buildability of the printed layers. Infrared (IR) reflectance feedback system measures the surface reflectance of the printed layers. The concrete printing setup is operated using an ATmega-2560 microcontroller on Arduino integrated development environment (IDE) [45]. Three self-compacting concrete mixes are considered, which have identical workability but different water-to-cement ratios. Fresh-state properties of printed concrete, namely, shape stability, buildability, layer moisture, surface moisture, infrared surface reflectance, and early-age shrinkage are studied. Properties of printed concrete after hardening, namely, pore size, shear strength, and compressive strength, are also studied.

Section 2 of the paper presents the details of the concrete printing set-up. Details of self-compacting concrete mixes considered for printing are presented in Section 3. Test methods used to characterize the properties of freshly-printed concrete are described in Section 4. Properties of freshly-printed concrete are presented in Sections 5. Effect of heating on the evolution of buildability is presented in Section 6 . Properties of hardened concrete are presented in Section 7. 


\section{Concrete printing set-up}

The process of printing concrete involves deposition of a layer of concrete on a printing platform, and heating the printed layer until "buildability" is achieved. The next layer is then printed and the cycle is continued. Figure 2 shows the concrete printing set-up developed at IIT Gandhinagar. Details on the components of the printer are presented in sections below.

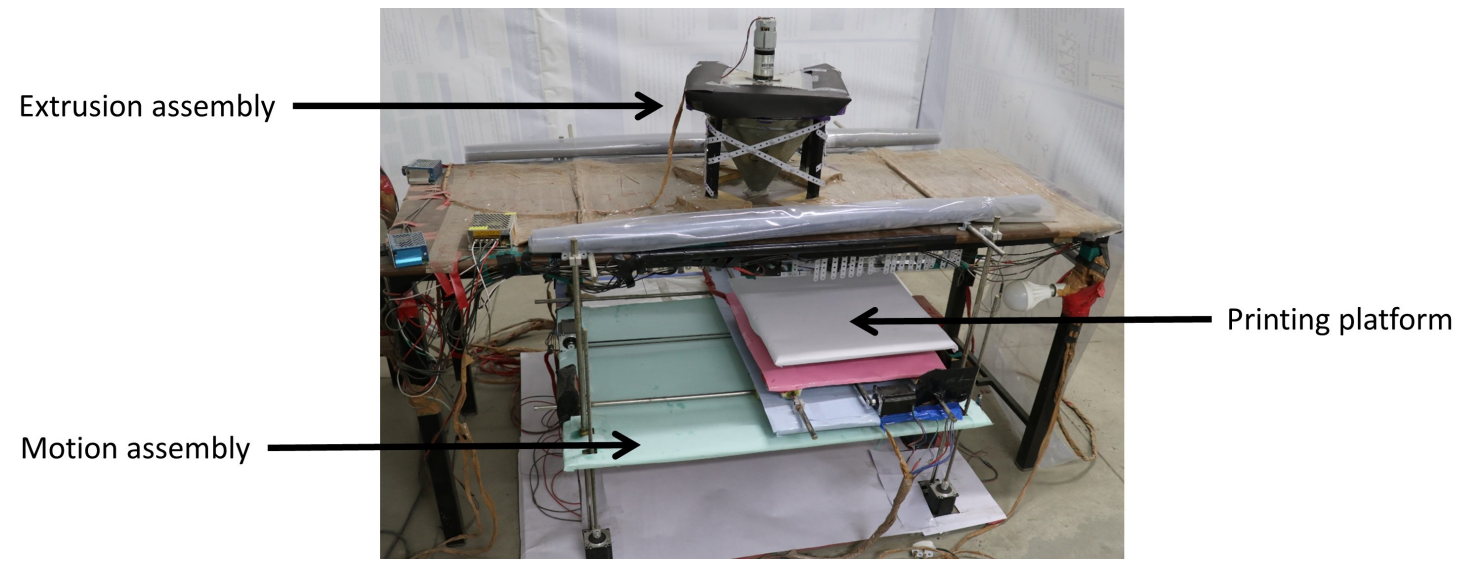

Figure 2: Concrete printing set-up at IIT Gandhinagar (adapted from [46])

\subsection{Motion assembly}

Motion assembly enables the translation of the printing platform independently in the three orthogonal directions (two horizontal, one vertical). The assembly comprises of stepper motors [47], threaded rods, pulley-belt system, guiding rails, and the top platform that is connected to the printing platform with a workspace of $300 \mathrm{~mm} \times 300 \mathrm{~mm} \times 300 \mathrm{~mm}$. Figure $3(\mathrm{a})$ shows the schematic of the vertical motion assembly, wherein four stepper motors are placed with their shafts along the threaded rods. This set-up facilitates the vertical movement of the horizontal motion assembly. The horizontal motion assembly enables the horizontal movement of the top platform along the two orthogonal horizontal directions (see Figure 3(b)). Figure 3(c) shows the schematic of the complete motion assembly.

\subsection{Extrusion assembly}

Extrusion assembly is used to extrude the fresh concrete through a nozzle onto the printing platform. The assembly comprises of a 250 watt direct current (DC) motor (torque capacity of $200 \mathrm{~kg}$-cm, and maximum revolution per minute (rpm) of 200), 25 mm-diameter steel screw, rigid coupling, conical hopper, nozzle with an inside diameter of $20 \mathrm{~mm}$, and a load cell with capacity of $40 \mathrm{~kg}$ mounted between the printing platform and the top platform. Figure 4 shows the schematic of the extruder that remains static during the printing (also see Figure 2). The rate of printing is controlled using a proportional-integral-derivative (PID) control algorithm (e.g., [48]). 


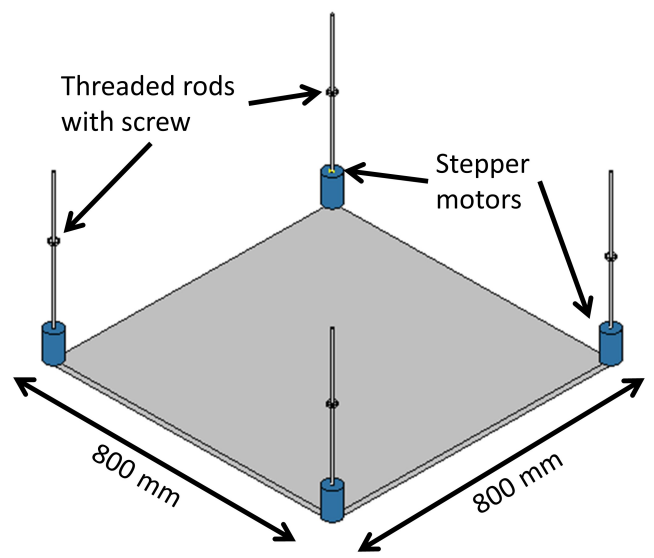

(a) Vertical motion assembly

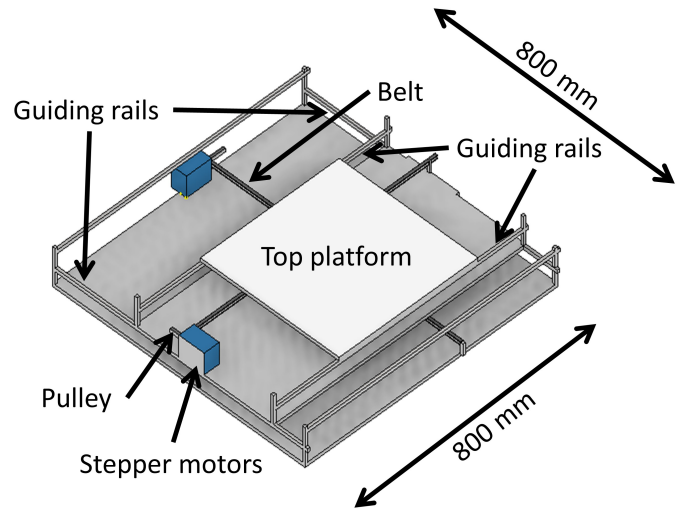

(b) Horizontal motion assembly

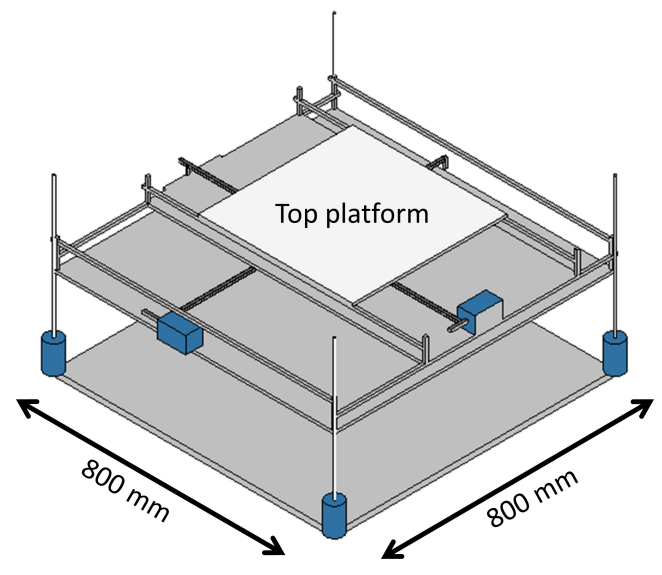

(c) Vertical and horizontal motion assembly

Figure 3: Motion assembly of the concrete printer (adapted from [46])

\subsection{Heating system}

Heating system comprises of two commercially available 1,000 Watt quartz radiation heaters and six $12 \mathrm{~V}$ DC fans (not shown in Figure 2). The system is mounted between the extrusion assembly and the printing platform. This system removes a portion of moisture from the printed layer, which changes the texture of the printed surface. Figure 5 shows the surface of freshly-printed concrete before (glossy texture) and after (matt texture) heating.

\subsection{Infrared reflectance feedback system}

The infrared (IR) reflectance feedback system comprises of an array of IR reflectance sensors (see Figure 6) mounted between the extruder and the top of motion assembly. An IR sensor consists of an infrared wave emitter and a photo-transistor (e.g., [49]) receiver. The IR waves generated by the emitter are partially reflected from the printed surface, and the intensity of the reflected wave is detected using the photo-transistor receiver. A 10 bit ATmega2560 microcontroller converts the analog signal received from the IR sensor to a digital signal valued between 0 and 1023, where 0 corresponds to a perfectly 


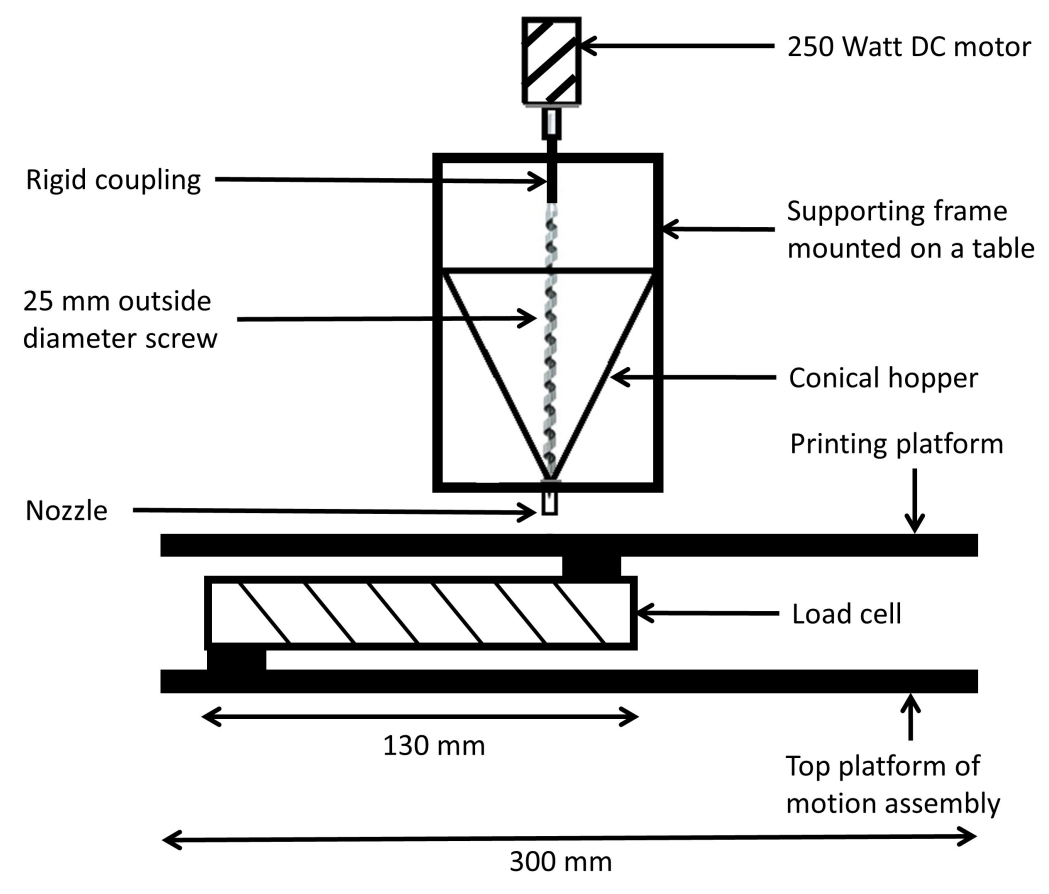

Figure 4: Schematic of the static extruder and the printing platform (drawing not to scale)

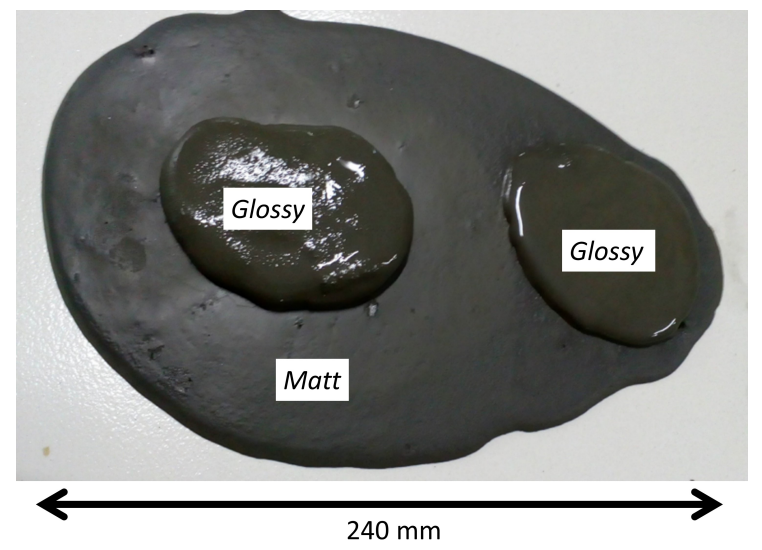

Figure 5: Freshly-printed concrete surface before and after heating (adapted from [46])

\section{Self-compacting concrete mixes}

Method proposed by Aitcin [50] was followed to design a self-compacting concrete mix (referred to as "HSC1") with a target mean strength of $80 \mathrm{MPa}$ after 28 days. Ordinary Portland cement (OPC) of 53 grade per IS 12269 [51] was used (make: Ultratech). Water-to-cement and cement-to-sand ratios were kept at 0.32 and 1.65 (by mass), respectively. Ten percent silica fume (\% of cement by mass) was added to increase the packing density and viscosity [50]. Coarse aggregates were not used. Workability of the mix was increased by adding $1.1 \%$ (\% of cement by mass) ASTM Type-F polycarboxylate ether- 


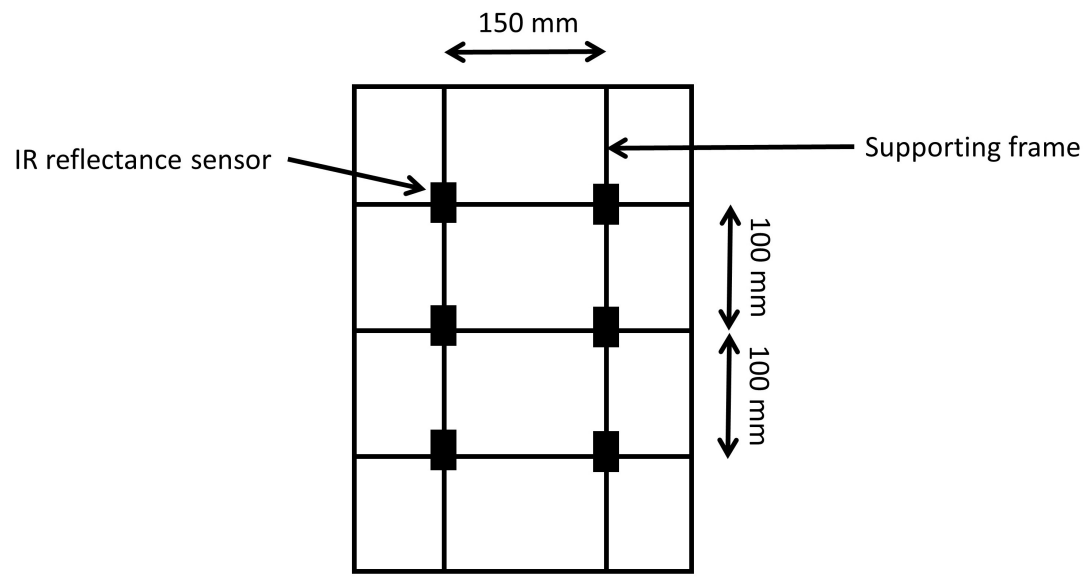

Figure 6: Infrared reflectance sensor array (drawing not to scale)

based superplasticizer [52] (make: Agrosyn Impex). The concrete mix had $744 \mathrm{~kg}$ cement, 1,227 kg sand, $75 \mathrm{~kg}$ silica fume, $238 \mathrm{~kg}$ water, and $8 \mathrm{~kg}$ superplasticizer per cubic meter. The mix had a flow table spread [53] of $270 \mathrm{~mm}$. Two more concrete mixes HSC2 and HSC3 were prepared, which had water-to-cement ratios 0.36 and 0.40 , respectively. Suitable amounts of superplasticizers were added to the two mixes so that their flow table spreads were same as HSC1 mix. Other parameters, namely, cement-to-sand and cement-to-silica fume were identical for the three mixes. Table 1 summarizes the details of the three mixes.

Table 1: Proportion (by mass) of ingredients in concrete mixes

\begin{tabular}{|c|c|c|c|c|c|}
\hline Mix ID & OPC & Silica fume & Sand & Water & Superplasticizer \\
\hline HSC1 & 1 & 0.1 & 1.65 & 0.32 & 0.011 \\
\hline HSC2 & 1 & 0.1 & 1.65 & 0.36 & 0.005 \\
\hline HSC3 & 1 & 0.1 & 1.65 & 0.40 & 0.002 \\
\hline
\end{tabular}

Roussel [54] had proposed an expression to calculate yield strength of fresh concrete $\left(\tau_{0}\right)$ based on mini-cone spread:

$$
\tau_{0}=1.747 \rho V^{2} R^{-5}-\lambda R^{2} / V
$$

where, $\rho$ is density of concrete, $V$ is volume of mini-cone, $R$ is mini-cone spread, and $\lambda$ is a function of surface tension and contact angle of the SCC mix. Mini-cone spread for the three mixes of Table 1 were $168 \mathrm{~mm}, 170 \mathrm{~mm}$ and $162 \mathrm{~mm}$, respectively. Since the mini-cone spread was lower than $350 \mathrm{~mm}$, the surface tension effects were neglected in the yield strength calculations [54]. Accordingly, initial yield strength of the three mixes were $27 \mathrm{~Pa}, 25 \mathrm{~Pa}$ and $33 \mathrm{~Pa}$, respectively.

\section{Tests to characterize fresh-state properties of printed concrete}

Tests were carried out to characterize the following properties of freshly-printed concrete: 1) shape stability, 2) buildability, 3) layer moisture, 4) surface moisture, 5) infrared surface reflectance, and 6) early-age 
shrinkage. Following sections present the details of the tests.

\subsection{Shape stability}

Shape stability test was carried out to determine the thickness of a freshly-printed layer that remains "stable" under gravity. The test set-up comprises of hollow cylinders with an inner diameter of $20 \mathrm{~mm}$, and heights of $30 \mathrm{~mm}, 20 \mathrm{~mm}, 15 \mathrm{~mm}, 10 \mathrm{~mm}, 8 \mathrm{~mm}, 6 \mathrm{~mm}$ and $4 \mathrm{~mm}$ (see Figure 7). A cylinder is first filled with an SCC mix. The cylinder is then pulled upwards (e.g., in slump test). No visible change in height and diameter of the cylinder-shaped SCC specimen indicates shape stability.

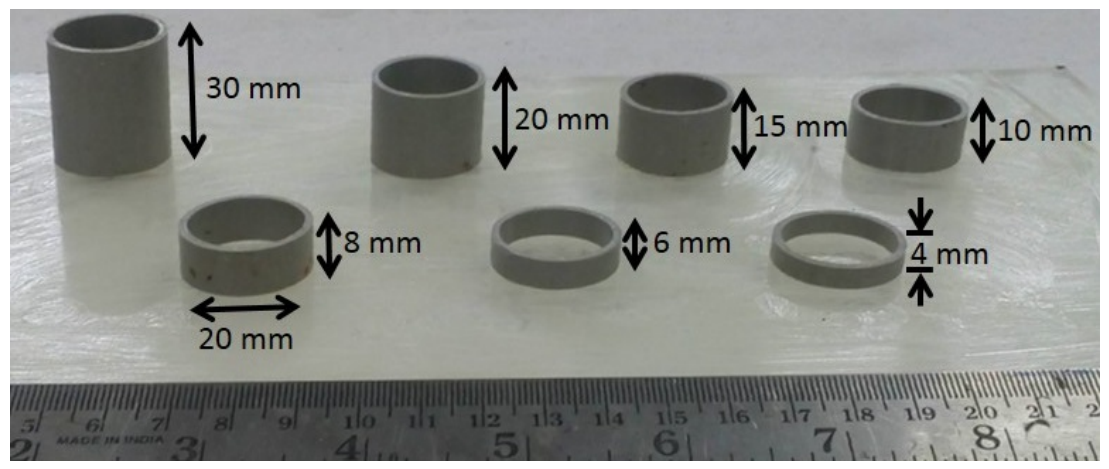

Figure 7: Shape stability test set-up

\subsection{Buildability}

Two measures to characterize buildability were considered: 1) compressive strength of printed specimens, and 2) yield strength of printed layers determined through a Vicat penetration test. Details of the two approaches are presented in the sections below.

\subsubsection{Compressive strength test}

A compression testing set-up with a capacity of $300 \mathrm{~N}$ was developed. The set-up also comprised of two heat guns of 1,000 watt each and an IR reflectance feedback array with five IR sensors (see Section 2.4). Figure 8 shows the schematic of the compression testing set-up. Figure 9 shows the compression testing set-up developed at IIT Gandhinagar. Variation in the reflectance of the printed surface could be recorded, while the surface was being heated. A caulking gun shown in Figure 10 (e.g., [21]) was used for printing specimens for this test. A fresh concrete layer was printed on a metal plate first, and was then placed in the test set-up. The layer was heated in the set-up using the two heat guns placed at an angle of $10^{\circ}$ with respect to the horizontal and pointing towards the surface of the freshly-printed layer. The approximate horizontal distance between the nozzle of the heat guns and the printed layer was $150 \mathrm{~mm}$. The printed layer was taken out after a specified duration of heating and next layer was printed. The procedure was followed to prepare a specimen with desired number of 


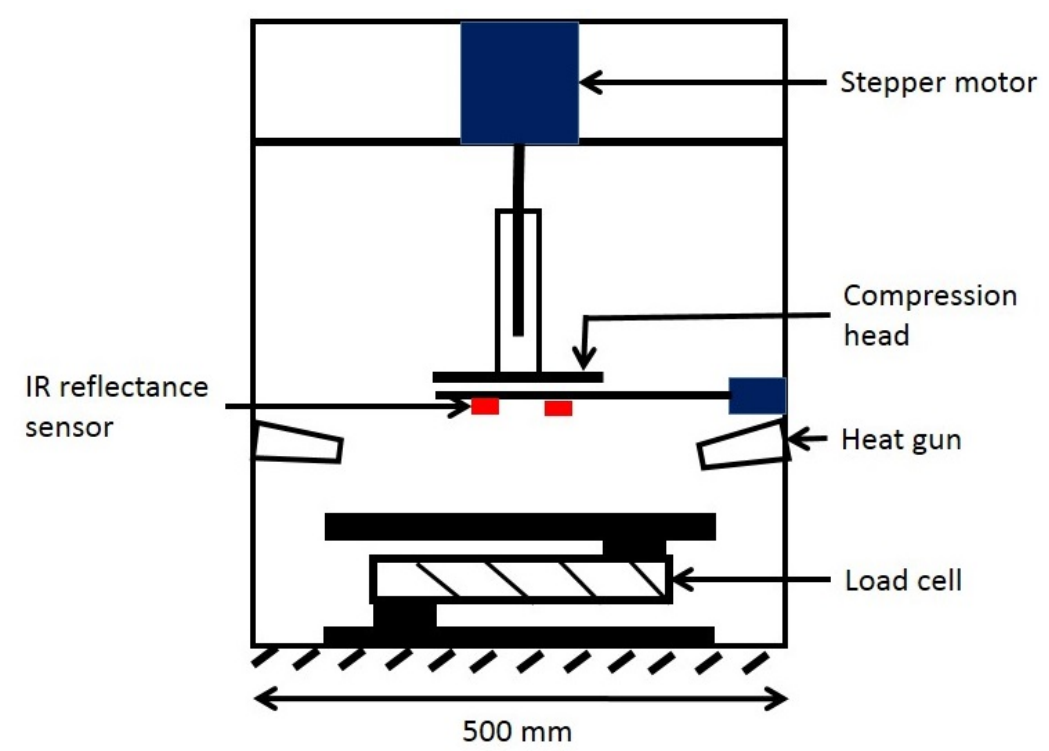

Figure 8: Schematic of compression testing set-up (drawing not to scale)

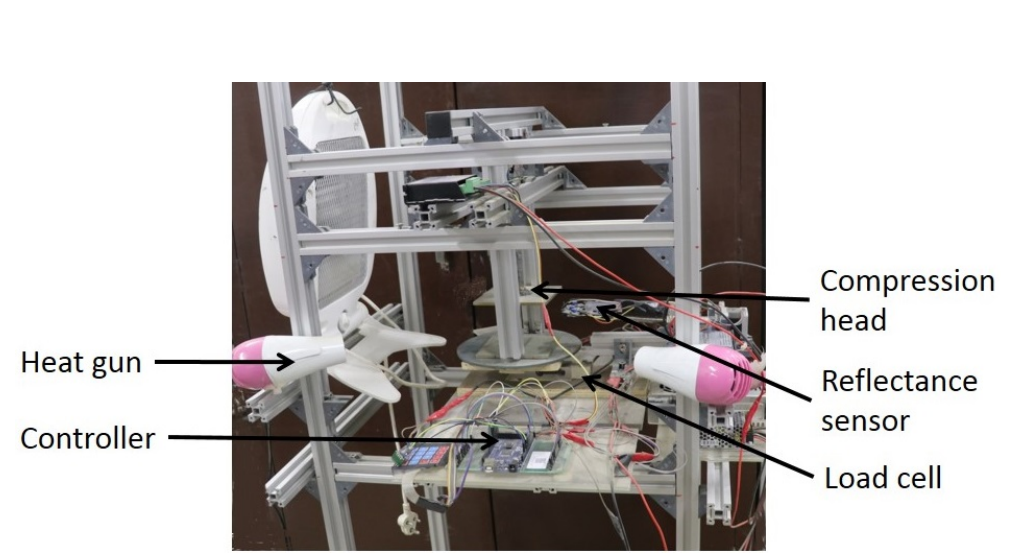

Figure 9: Compression testing set-up

layers. A piece of chosen size was cut from the printed specimen, which would then be subjected to the compression test.

\subsubsection{Vicat penetration test}

Penetration of Plunger G used for the Vicat standard consistency test [55] in a printed specimen was used to determine yield strength of the printed specimen [56]. The yield strength is considered the second measure of buildability. The caulking gun of Figure 10 was used to print a layer on a metal plate. The layer was heated using two 1,000 Watt heat guns arranged with respect to the printed specimen in a manner similar to the compression testing set-up. The penetration test was conducted after printing a sufficient number of layers, and the yield strength $\left(\tau_{0}\right)$ was determined using the following expression $[56]:$

$$
\tau_{0}=F /(2 \pi R h)
$$


where, $h$ is the penetration depth of Plunger $\mathrm{G}$, and $R$ and $F$ are radius $(=5 \mathrm{~mm})$ and weight of Plunger (=300 grams), respectively.

\subsection{Layer moisture}

Specimens to determine the moisture in a layer during heating were printed using the caulking gun of Figure 10. A printed layer was placed on a weighing balance with 0.01 gram resolution, and was heated in a manner similar to the Vicat test. Change in weight of the printed layer was manually recorded every 10 seconds. The change indicates the loss of moisture in the layer due to heating.

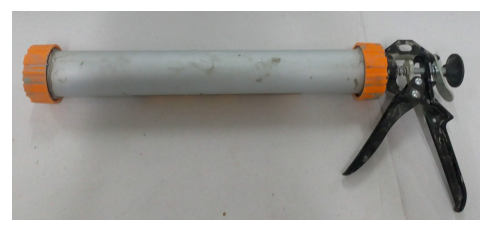

Figure 10: Caulking gun

\subsection{Surface moisture}

Surface moisture in a printed layer was measured using the method proposed by Sanjayan et al. [16]. The layer was prepared using the caulking gun of Figure 10, and it was heated in the manner similar to the Vicat test. Subsequently, a paper towel with plan dimensions same as the printed layer was placed on the printed layer for a duration of 20 seconds. Increase in the weight of the paper towel was taken as surface moisture.

\subsection{Infrared surface reflectance}

Specimens to determine IR surface reflectance of a printed layer were prepared using the caulking gun. The printed specimen was placed in the compression testing set-up. The specimen was heated and the surface reflectance was measured in parallel using the array of five IR sensors placed in the compression testing set-up (see Section 4.2).

\subsection{Early-age shrinkage}

A concrete layer with plan dimensions of $300 \mathrm{~mm} \times 100 \mathrm{~mm}$ was printed using the caulking gun on a lubricated granite slab. Two light-weight reflectors were placed centrally and $250 \mathrm{~mm}$ apart on the printed layer. The layer was heated in a manner similar to the Vicat test. Change in distance between the reflecting surfaces was measured using two SHARP GP2Y0A51SK0F analog IR laser distance sensors, and an Arduino Due-R3 ARM-Cortex-M3 control board was used to record the data. Figure 11 shows the schematic of the early-age shrinkage test set-up and Figure 12 shows the actual set-up. 


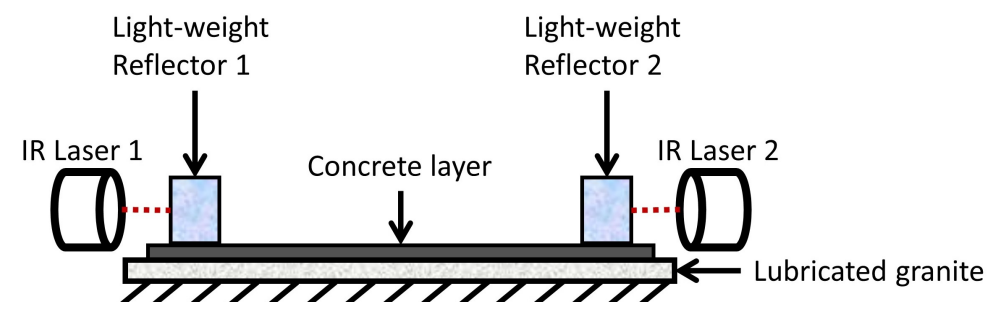

Figure 11: Schematic of the shrinkage test set-up (drawing not to scale)

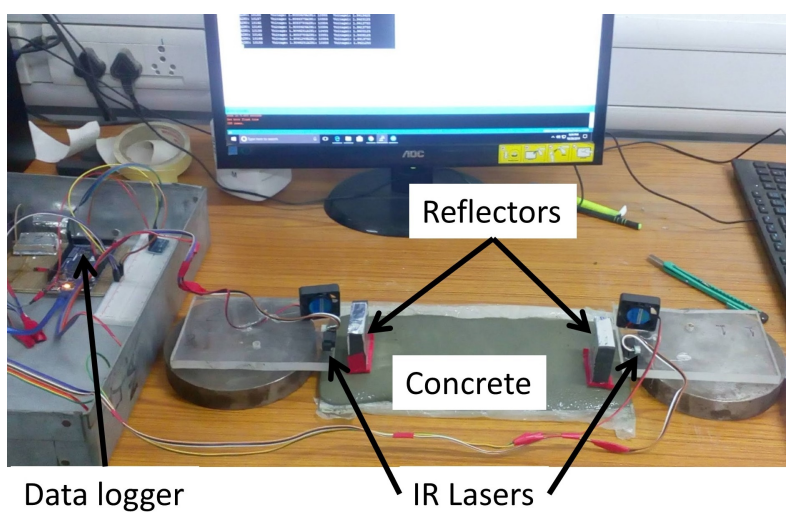

Figure 12: Shrinkage test set-up

\section{Properties of freshly-printed concrete}

Properties of freshly-printed concrete identified in Section 4 were determined for the three mixes presented in Table 1. The results are presented in the sections below.

\subsection{Shape stability}

The hollow cylinders shown in Figure 7 were filled with fresh HSC1 mix, and the cylinders were pulled out immediately. The final shapes of the specimens with initial heights $8 \mathrm{~mm}$ or greater were substantially different compared to the respective initial shapes, as seen in Figure 13. The final shapes for specimens with $6 \mathrm{~mm}$ and $4 \mathrm{~mm}$ heights were comparable to their respective initial shapes. Observations for HSC2 and HSC3 mixes were similar to HSC1. These results can be a basis for determining the layer thickness (controlled through flow rate) during printing.

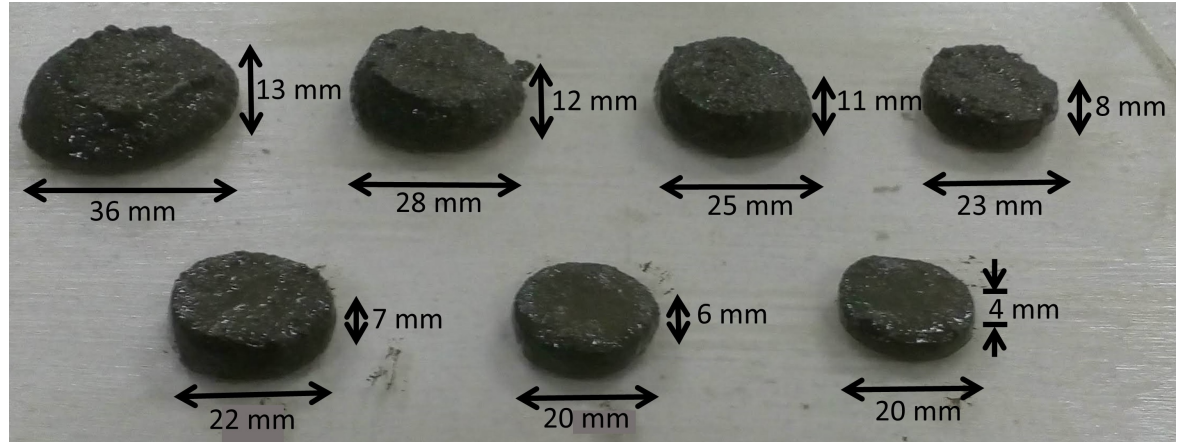

Figure 13: Shape stability test of HSC1 Mix 


\subsection{Buildability}

\subsubsection{Compressive strength test}

A layer of HSC1 mix (see Section 3) was printed on a metal plate using the caulking gun. The plate was placed in the compression testing set-up (see Section 4.2). The layer was heated for 60 seconds. A second layer could not be printed if the printed layer was heated for a duration less than 60 seconds. The metal plate was taken out of the test set-up, and another layer was printed and heated for 60 seconds. This process was carried out a total of five times. Figure 14 shows the plate with five printed layers placed in the test set-up. Total thickness of the five layers was $30 \mathrm{~mm}$. A cube of size $30 \mathrm{~mm} \times 30 \mathrm{~mm}$ $\times 30 \mathrm{~mm}$ was prepared from the specimen of Figure 14. The cube was placed back in the compression test set-up, as shown in Figure 15. The compressive strength test started a total of 20 minutes after water was added to the HSC1 mix. Compression head of the test set-up was lowered 2 mm every minute (e.g., [57]).

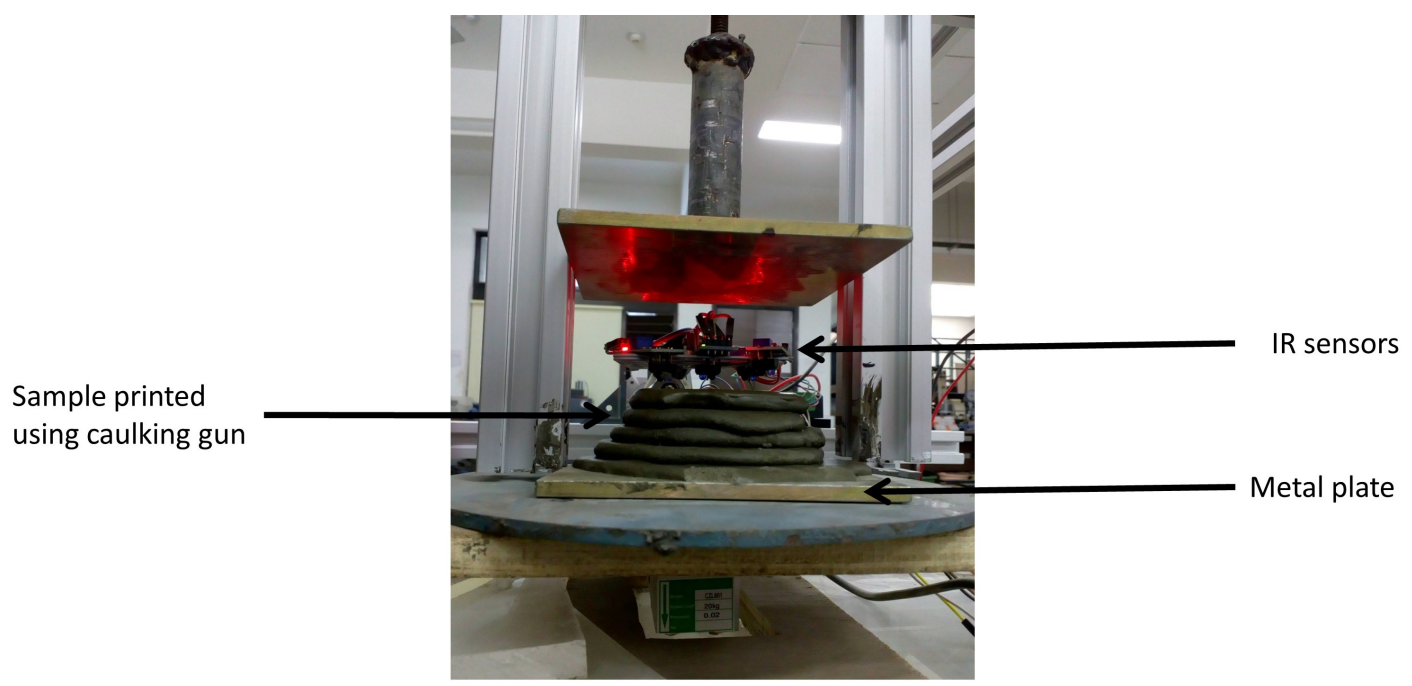

Figure 14: Sample preparation for compression testing of freshly-printed concrete

Figure 16(a) plots recorded compressive force against axial strain in the cube ${ }^{1,2}$. The cube could be loaded without experiencing any visible cracks till an axial strain of approximately $6 \%$. Results for mixes HSC2 and HSC3 are presented in panels (b) and (c) of Figure 16, respectively. Strains corresponding to first visible cracks for the two specimens was $8 \%$ and $9 \%$, respectively. Figure 16 also presents the results for specimens with layers heated for 120 and 180 seconds. Strains corresponding to the first visible cracks for $\mathrm{HSC} 1$ (HSC2, HSC3) mix was $6 \%(7 \%, 5 \%)$ and $4 \%(7 \%, 7 \%)$ corresponding to the two durations of heating, respectively. It is proposed to define buildability as the axial stress in the

\footnotetext{
${ }^{1}$ The test set-up was loaded without any specimen and deformation per unit load (also known as compliance) was determined to be $0.015 \mathrm{~mm} / \mathrm{N}$.

${ }^{2}$ Total deformation recorded by the compression test set-up is the sum of actual deformation in the specimen and deformation in the test set-up itself. Axial strain in the specimen was calculated as the ratio of actual deformation in the specimen to original height $(30 \mathrm{~mm}$ in the present case).
} 


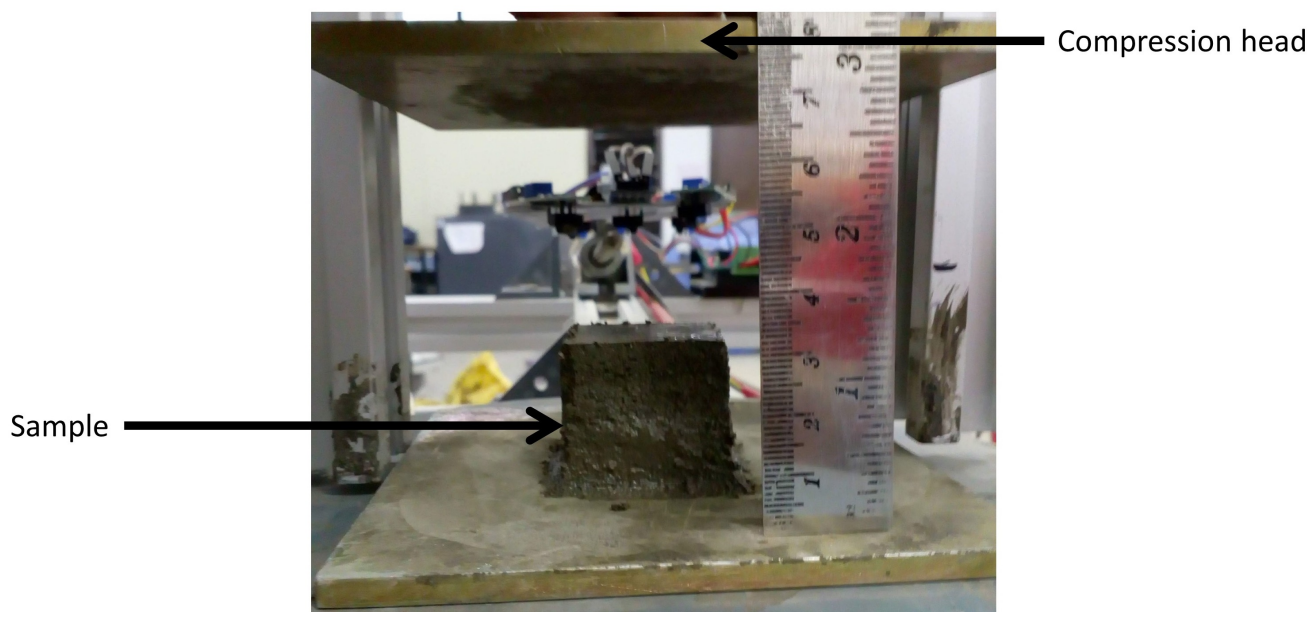

Figure 15: Cube cut from the printed specimen placed in compression test set-up

cube corresponding to an axial strain of $5 \%$. Buildability for the three mixes and the three durations of heating are presented in Table 2. Buildability was higher for a smaller water-to-cement ratio and/or a longer duration of heating.

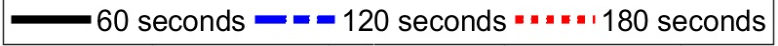

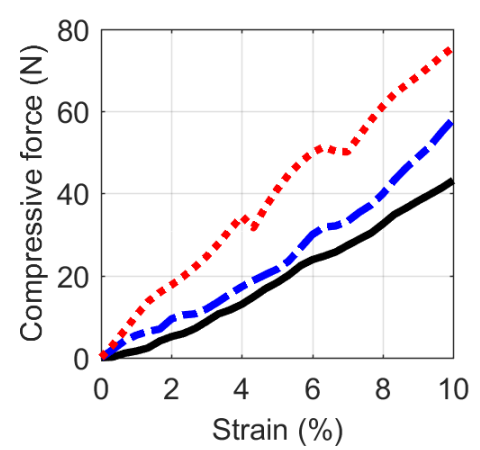

(a) HSC1

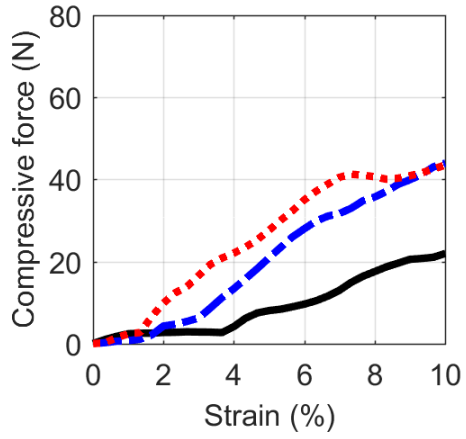

(b) HSC2

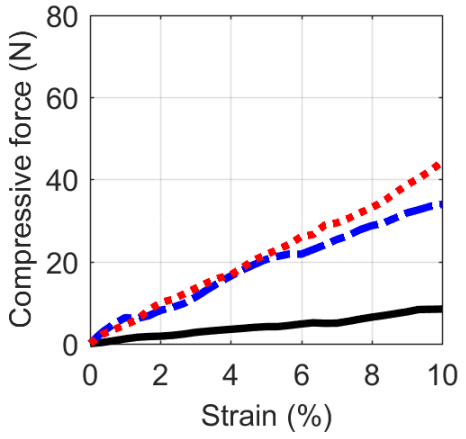

(c) HSC3

Figure 16: Axial force-strain response of cubes

Table 2: Buildability of freshly-printed concrete obtained through compressive strength tests

\begin{tabular}{|c|c|c|c|}
\hline \multirow{2}{*}{ Heating duration (s) } & \multicolumn{3}{|c|}{$\begin{array}{c}\text { Compressive strength } \\
\text { at 5\% axial strain (kPa) }\end{array}$} \\
\cline { 2 - 4 } & HSC1 & HSC2 & HSC3 \\
\hline 60 & 20.3 & 8.9 & 4.5 \\
\hline 120 & 23.9 & 23.2 & 22.8 \\
\hline 180 & 45.5 & 30.7 & 24.1 \\
\hline
\end{tabular}

\subsubsection{Vicat penetration test}

A $6 \mathrm{~mm}$-thick layer of HSC1 mix was printed using the caulking gun on a metal plate, and was heated using two 1,000 Watt heat guns for 60 seconds. Subsequently, two more layers were printed 
through the same process (total thickness of printed specimen was $18 \mathrm{~mm}$ ). The Vicat test plunger for standard consistency test (Vicat Plunger G according to IS 5513 [55]) penetrated the printed specimen $6 \mathrm{~mm}$ deep (yield strength $15.9 \mathrm{kPa}$ per Eq. 2). This test was conducted approximately six minutes after water was added to the dry mix. Subsequent to the penetration test, the printed surface was heated again for 60 seconds. The penetration test was carried out again. The plunger could penetrate the specimen $1 \mathrm{~mm}$ deep (yield strength of $95.5 \mathrm{kPa}$ ). The surface was heated again for 60 seconds, and the penetration test was conducted. The plunger could not penetrate the specimen. These results are summarized in Table 3. Results for HSC2 and HSC3 mixes are also presented in Table 3. Buildability decreased with an increase in water-to-cement ratio, and increased with an increase in duration of heating.

Table 3: Buildability of freshly-printed concrete through Vicat penetration test

\begin{tabular}{|c|c|c|c|c|c|c|c|c|}
\hline \multicolumn{2}{|c|}{ Heating duration (s) } & \multicolumn{3}{c|}{ Penetration (mm) } & \multicolumn{3}{c|}{ Yield strength (kPa) } \\
\hline Layer 1 & Layer 2 & Layer 3 & HSC1 & HSC2 & HSC3 & HSC1 & HSC2 & HSC3 \\
\hline 60 & 60 & 60 & 6 & 7 & 8 & 15.9 & 13.6 & 11.9 \\
\hline 60 & 60 & 120 & 1 & 2 & 4 & 95.5 & 47.7 & 23.8 \\
\hline 60 & 60 & 180 & 0 & 0 & 1 & - & - & 95.5 \\
\hline
\end{tabular}

\subsection{Layer moisture}

A layer of HSC1 mix was printed using the caulking gun. Plan dimension of the printed layer was $80 \mathrm{~mm} \times 80 \mathrm{~mm}$, and the layer was $6 \mathrm{~mm}$-thick. Total mass of the printed layer was 98.4 grams and the amount of water in the printed layer was 10.2 grams. The printed layer was placed on the weighing machine and heating was initiated. Details of the set-up are presented in Section 4.3. Figure 17(a) presents the total mass of the printed layer with time. Figure 17(b) presents the moisture content (ratio of the mass of available water in the printed layer to that of dry mix) in the layer with time. Approximately $1 \%$ moisture was lost after 60 seconds of heating.

\subsection{Surface moisture}

A layer of HSC1 mix with plan dimensions of $250 \mathrm{~mm} \times 25 \mathrm{~mm}$ was printed using the caulking gun. Surface moisture was measured using the method proposed by Sanjayan et al. [16] (see Section 4). Gain in the weight of the paper towel was 0.7 grams, which represents the surface moisture of freshly-printed layer [16]. A similar layer of HSC1 mix was printed, and heated for a duration of 60 seconds. The layer was immediately covered with a paper towel for 20 seconds to measure the surface moisture of HSC1 mix after 60 seconds of heating. This process was repeated to measure the surface moisture after 120 and 180 seconds of heating. Similar exercise was conducted for HSC2 and HSC3 mixes. Figure 18 presents the variation of the surface moisture with heating durations mentioned above. Surface moisture decreased with increasing duration of heating for the mixes considered. 


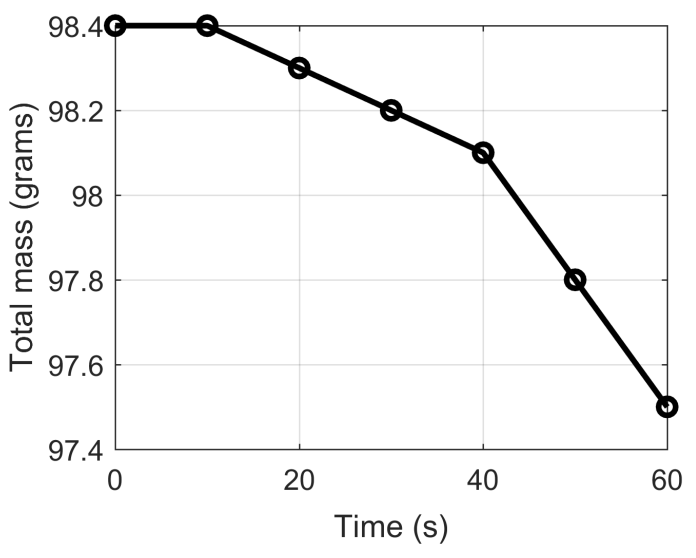

(a) Total mass of printed layer

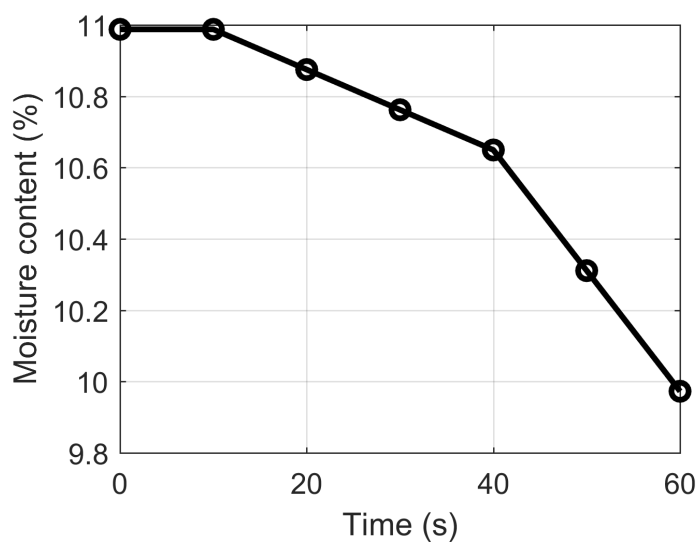

(b) Moisture content

Figure 17: Moisture in a printed layer

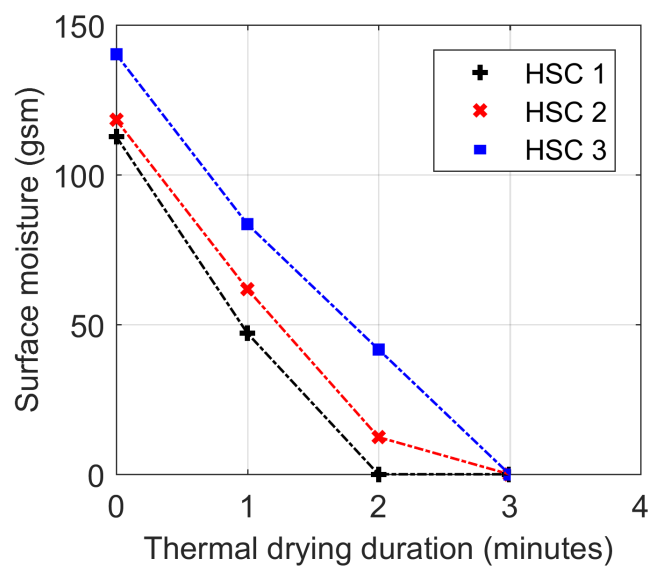

Figure 18: Surface moisture in a printed layer

\subsection{Infrared surface reflectance}

A layer of HSC1 mix (see Section 3) was printed on a metal plate using the caulking gun. The plate was placed in the compression test set-up (see Section 4.5). Heating was initiated along with the IR reflectance measurement of the printed surface. This process lasted for about 60 seconds, at the end of which the surface of the printed layer acquired a matt texture (as observed visually). The metal plate was taken out of the test set-up, and another layer was printed and heated for 60 seconds. This process was carried out a total of five times. Figure 14 shows the plate with five printed layers placed in the test set-up.

Figure 19(a) presents the average of the surface reflectance measured using the five sensors of the reflectance array plotted against time for the first layer printed. The average value increased from 671 to 722 in the 60 seconds of heating, during which the surface texture changed from glossy to matt. Figure 19(b) presents the results for the second layer. The initial average value of reflectance was 593. The difference compared to the first layer can be attributed to the manual placement of the metal plate 


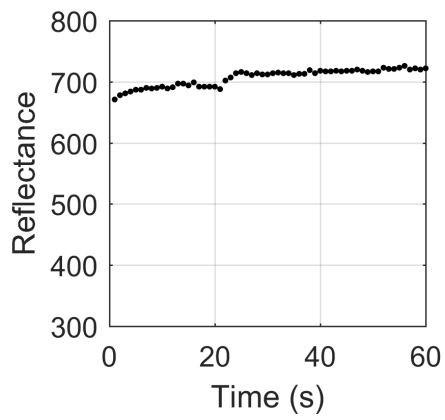

(a) Layer 1

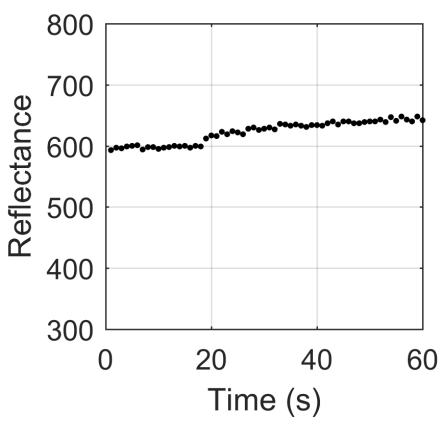

(b) Layer 2

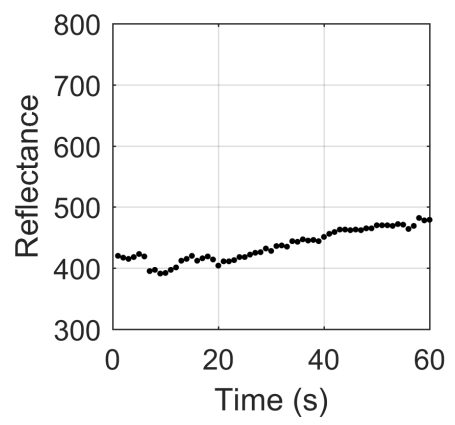

(c) Layer 3

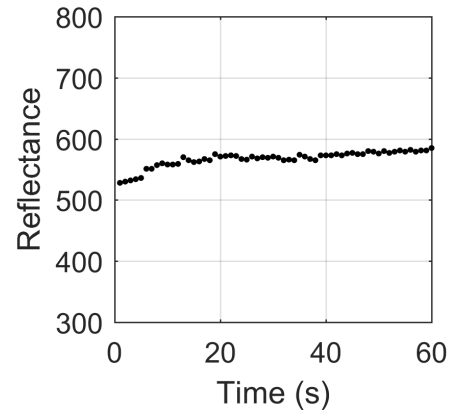

(d) Layer 4

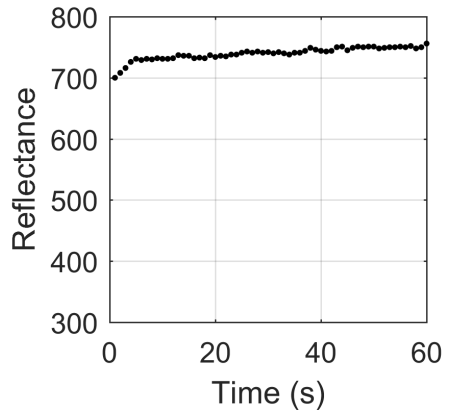

(e) Layer 5

Figure 19: Average reflectance at the surface of printed layer

\subsection{Early-age shrinkage}

A layer of HSC1 mix was printed on the lubricated granite base of the shrinkage test set-up (see Section 4.6). The specimen was kept undisturbed for 500 minutes, during which the reflectors came closer by 19 microns (a shrinkage strain of $75 \times 10^{-6}$ ). Figure 20(a) presents the history of shrinkage for the printed layer. Similarly, the reflectors came closer by 24 microns and 45 microns for HSC2 and HSC3 mixes, and corresponding shrinkage strains were $96 \times 10^{-6}$ and $180 \times 10^{-6}$, respectively. Corresponding histories of shrinkage are presented in panels (b) and (c) of Figure 20, respectively.

Another layer of HSC1 mix was printed on the lubricated granite slab. The layer was heated for 60 seconds. The reflectors first moved away from each other by 24 microns (expansive strain of $96 \times 10^{-6}$ ), and then came closer to each other by 43 microns (shrinkage strain of $172 \times 10^{-6}$ ) at the end of 500 minutes. Corresponding shrinkage history is presented in Figure 20(a). These results for HSC2 and HSC3 mixes are presented in panels (b) and (c) of Figure 20, respectively. It is clear from the figure 
that 1) maximum shrinkage was achieved much faster when the specimens were heated for 60 seconds compared to when they were not, 2) shrinkage was generally greater when the specimen was heated compared to when it was not, and 3) effect of heating on maximum shrinkage decreased with increase in water-to-cement ratio.

........ Unheated ----- Heated

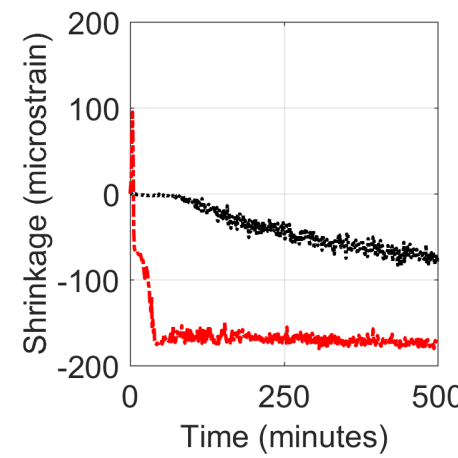

(a) HSC1 mix

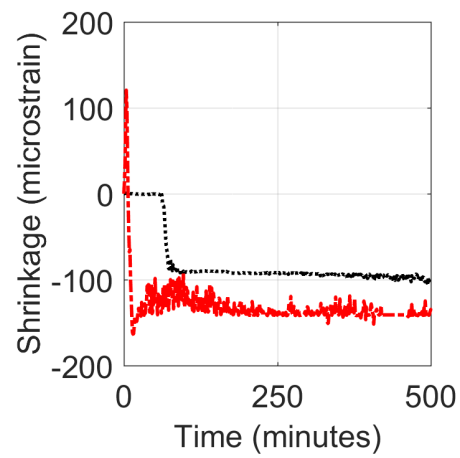

(b) HSC2 mix

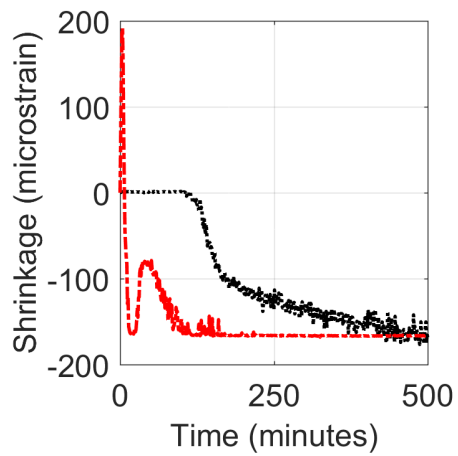

(c) HSC3 mix

Figure 20: Early-age shrinkage of printed layers

\section{Evolution of buildability}

As noted in Section 1, a concrete mix with a moderate initial yield strength (e.g., 1,500 Pa) is often used to print concrete. Admixtures are added to the mix to accelerate the setting process, thereby increasing the capacity of the printed layer to bear the weight of the layers above (or to increase buildability). Khalil et al. [13] studied the effect of adding an admixture in concrete mix on the evolution of buildability of printed concrete. Two binders were considered: 1) 100\% OPC, and 2) 93\% OPC mixed with $7 \%$ calcium sulpho-aluminate by weight. Yield strength of the two mixes were $2,618 \mathrm{~Pa}$ (15 minutes after water was added to dry mix) and 2,730 $\mathrm{Pa}$ (10 minutes after water was added to dry mix), respectively, as determined through the Vicat penetration test described in Section 4.2.2. The yield strength increased to 2,730 $\mathrm{Pa}(38,217 \mathrm{~Pa})$ and 95,541 $\mathrm{Pa}(95,541 \mathrm{~Pa})$ for the two mixes, respectively, 20 minutes (45 minutes) after water was added to the two mixes. Figure 21 presents the evolution of buildability in the two mixes.

Initial yield strength of HSC1 mix was $27 \mathrm{~Pa}$ per Eq. 1 (see Section 3). Yield strength of the mix was considered to increase linearly with time per the relationship below [58]:

$$
\tau_{o}(\Delta t)=\tau_{o}(0)+A_{t h i x} \Delta t
$$

where, $\tau_{o}(0)$ is the initial yield strength, $\tau_{o}(\Delta t)$ is the yield strength after time $\Delta t$, and $A_{t h i x}$ is the flocculation or structuration rate. Lecompte et al. [31] noted that the above relationship is applicable 


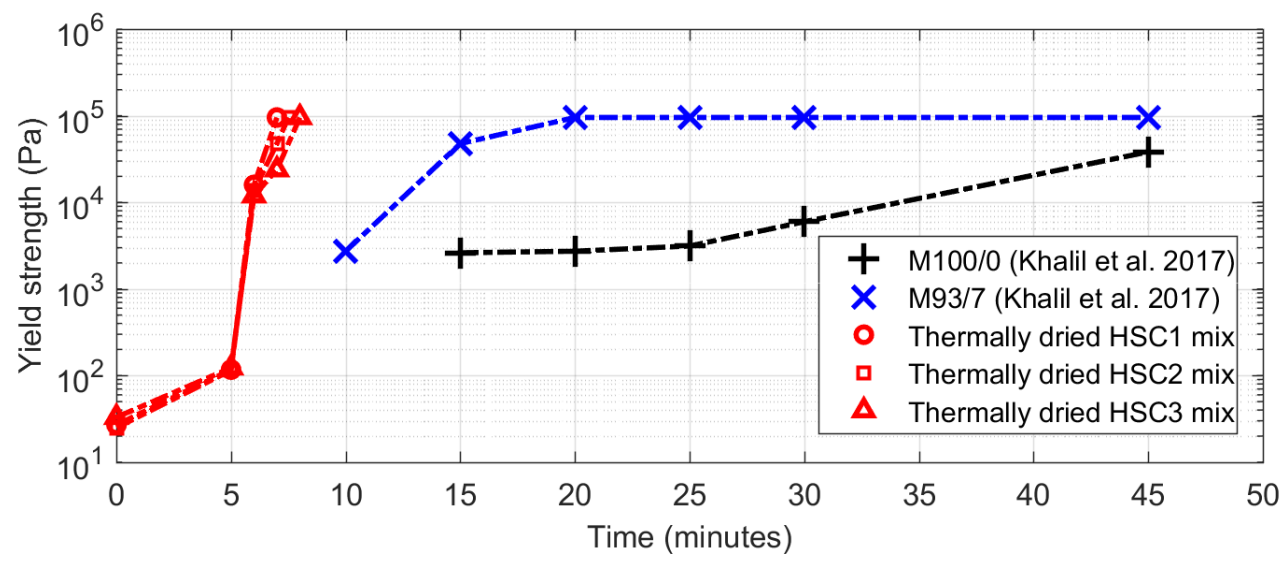

Figure 21: Evolution of buildability of printed concrete

only before setting of concrete has begun. Roussel [58] suggest that the flocculation rate for a thixotropic material can be considered to be $0.3 \mathrm{~Pa} / \mathrm{s}$. Yield strength of the mix was $117 \mathrm{~Pa}$ five minutes after water was added to the dry mix, assuming mix HSC1 is a thixotropic material. Subsequent values of yield strength of HSC1 mix are based on the Vicat test results reported in Section 5.2.2. Accordingly, the yield strength of the mix at the end of six minutes (60 seconds of heating) and seven minutes (120 seconds of heating) were 15,923 $\mathrm{Pa}$ and 95,541 $\mathrm{Pa}$, respectively. These results and those for HSC2 and HSC3 mixes are shown in Figure 21. It is clear that heating can lead to a much sharper rise in buildability compared to that obtained through the usage of chemical admixtures.

\section{Properties of printed concrete after hardening}

A layer of HSC1 mix was printed using the set-up described in Section 2. The plan area of the layer was $250 \mathrm{~mm} \times 250 \mathrm{~mm}$. Thickness of the layer was $6 \mathrm{~mm}$. The layer was heated for 60 seconds. A total of seven layers were printed using this approach. The printed specimen was covered with a moist cloth for 24 hours, and was kept in water for next 27 days. A total of 16 cubes were cut from the printed specimen, each with edges $40 \mathrm{~mm}$ long. A total of 48 such cubes were prepared for the combination of HSC1 mix and 60 seconds of heating for a layer. A total of nine combinations of mixes (HSC1, HSC2 and HSC3) and duration of heating (60 seconds, 120 seconds and 180 seconds) were considered. Forty eight cubes were prepared for each combination. Following properties of the printed concrete after hardening were studied through tests on the cubes: 1) pore size, 2) shear strength, and 3) compressive strength. Results are presented in the sections below.

\subsection{Pore size}

Figure 22 shows an enlarged view of the cut surface of a concrete cube (see Section 7). Pore size on the surface was measured using the "CTL Crack Comparator." The maximum pore size was $1 \mathrm{~mm}$ 
with most pores smaller than $0.4 \mathrm{~mm}$.

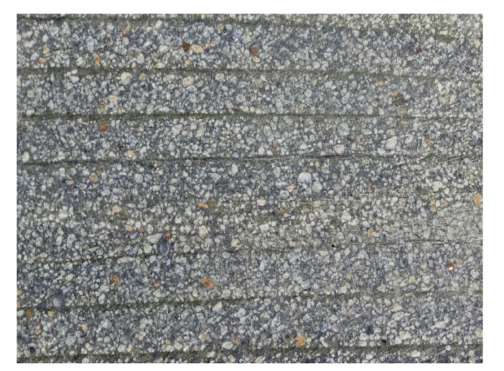

Figure 22: Printed concrete cross-section

\subsection{Shear strength}

Figure 23 shows the 300-ton Instron Compression Testing Machine (CTM) with a cube supported at the bottom from two sides and loaded at the top using a $10 \mathrm{~mm}$ thick plate. The nearest distance between the two supports is $12 \mathrm{~mm}$. This set-up enables a double shear strength test of a cube (e.g., [59]). Five cubes for each combination of mix and duration of heating were tested for shear strength with layers aligned parallel to the direction of loading. Figure 24 identifies the directions parallel and perpendicular to the printed layers in a $50 \mathrm{~mm}$-cube. Rate of loading the specimen was $1 \mathrm{~mm}$ per minute. Shear strength was calculated as the maximum load divided by the area under shear, i.e., $2 \times 40 \mathrm{~mm}$ $\times 40 \mathrm{~mm}$. Figures 25(a) presents the average shear strength of five cubes for each combination. Also presented in the figure are the average strength of three cubes (e.g., [60]) cast in moulds. Figure 25(b) presents the results for cubes tested with the printed layers perpendicular to the direction of loading.

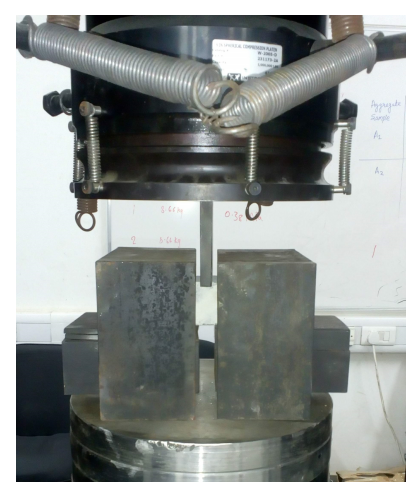

Figure 23: Shear strength test set-up

Average shear strength of mould-cast cubes of HSC1 mix was 4.2 MPa. The strength corresponding to a duration of heating of 60 seconds was $3.8 \mathrm{MPa}(4.0 \mathrm{MPa})$ for cubes tested parallel (perpendicular) to the layers. The strength was $3.3 \mathrm{MPa}(3.8 \mathrm{MPa})$ and $3.0 \mathrm{MPa}(3.9 \mathrm{MPa})$ corresponding to 120 seconds and 180 seconds of heating, respectively. The effect of duration of heating was smaller for greater water-to-cement ratios, in general. 


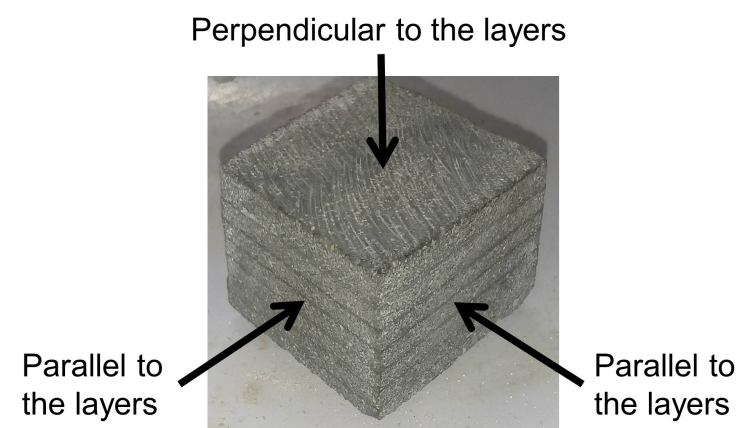

Figure 24: Printed concrete after hardening (adapted from [46])
- 60 seconds
120 seconds
180 seconds
Mould cast

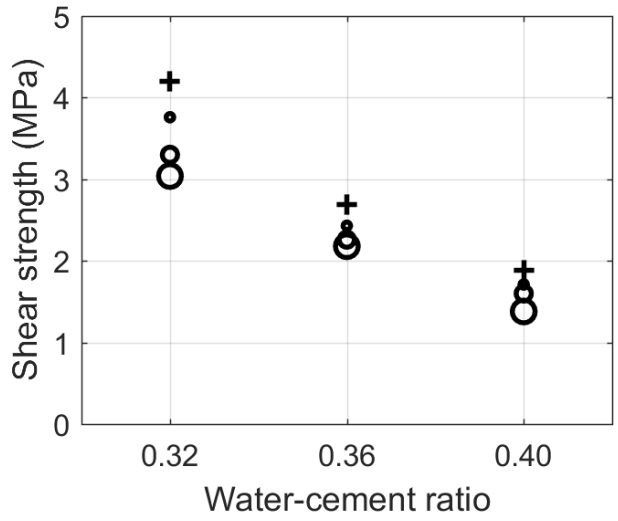

(a) Testing parallel to the layers

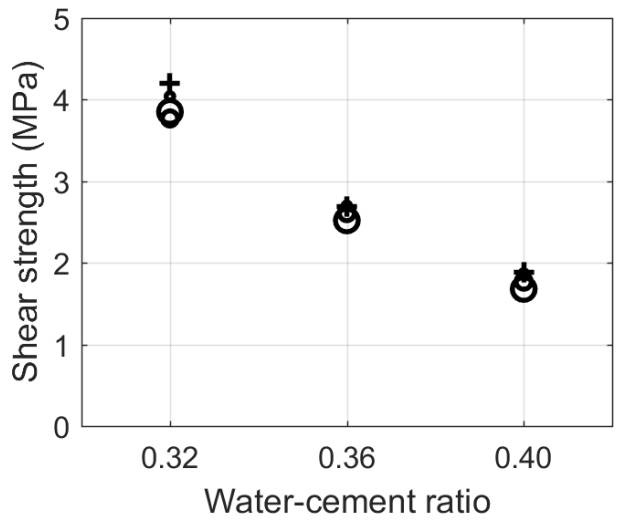

(b) Testing perpendicular to the layers

Figure 25: Average shear strength of concrete cubes

\subsection{Compressive strength}

Five cubes for each of the nine combinations of mix and duration of heating were tested for compressive strength in directions parallel and perpendicular to the layers. Compression testing was performed in accordance with IS 516 [61]. Figures 26(a) and 26(b) present the average compressive strength of printed cubes in directions parallel and perpendicular to the printed layers, respectively. Average compressive strength of three mould-cast specimens are also presented in the figure. Average compressive strength of mould-cast cubes of HSC1 mix was 71.6 MPa. The strength corresponding to a duration of heating of 60 seconds was $61.5 \mathrm{MPa}(65.7 \mathrm{MPa})$ for cubes tested parallel (perpendicular) to the layers. The strength was 54.2 $\mathrm{MPa}(62.2 \mathrm{MPa})$ and 49.1 $\mathrm{MPa}(56.4 \mathrm{MPa})$ corresponding to 120 seconds and 180 seconds of heating, respectively. The effect of duration of heating on the compressive strength was smaller for greater values of water-to-cement ratios. 
- 60 seconds $\mathbf{0} 120$ seconds $\mathbf{O} 180$ seconds + Mould cast

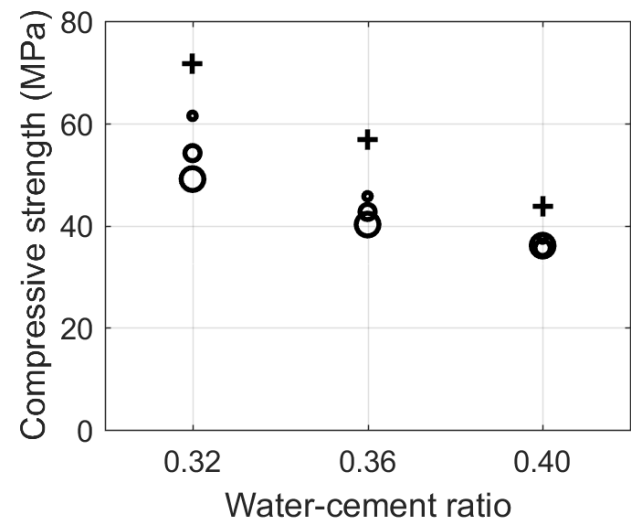

(a) Testing parallel to the layers

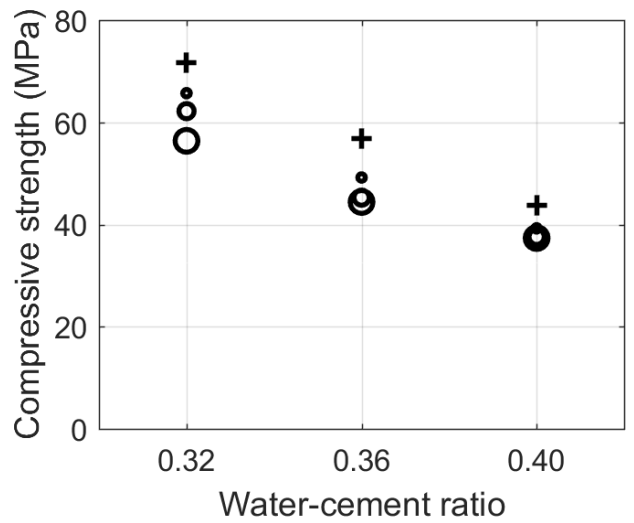

(b) Testing perpendicular to the layers

Figure 26: Average compressive strength of concrete cubes

\section{Conclusions}

A new method to print concrete through controlled heating of printed layers is developed. The method allows for printing of a self-compacting concrete mix with initial yield strength as low as $30 \mathrm{~Pa}$. The method offers following potential advantages over existing practices: 1) a better bonding between adjacent layers, 2) a sharper rise in buildability of the printed layers, and 3) a smaller possibility of choking in the printing set-up.

Properties of printed concrete in the fresh state were evaluated. It was concluded that a "stable" layer thickness for the considered SCC mixes can be $6 \mathrm{~mm}$. Buildability of the printed layers, i.e., the capacity to hold the layers above were characterized through two approaches, namely, direct compression test, and Vicat penetration test. The buildability was greater for a smaller water-to-cement ratio and/or a longer duration of heating. A longer duration of heating would be associated with a greater loss of moisture from the printed layer, and it may adversely affect the bonding between adjacent layers. A sufficient level of buildability was considered achieved when the texture of the printed surface had turned into matt. The same could be characterized through the measurement of surface reflectance of the printed surface. Early-age shrinkage in a printed layer was greater if the layer was subjected to heating for 60 seconds compared to when it was not. The difference was smaller for a greater water-tocement ratio. The "ultimate" early-age shrinkage was achieved faster when the printer layer was heated. For the mixes considered in the present study, the shrinkage strain was smaller than $200 \times 10^{-6}$.

A visual inspection of the printed specimens after hardening indicated that the size of the largest pore was $1 \mathrm{~mm}$, and that most pores were smaller than $0.4 \mathrm{~mm}$. Shear and compressive strength of printed cubes were found smaller when the direction of loading was parallel to the printed layers compared to when it was perpendicular. The effect of duration of heating was greater in the former case. As an 
example, the average compressive strength of a set of mould cast cubes was $71.6 \mathrm{MPa}$. The strength for the corresponding printed specimen was $61.5 \mathrm{MPa}$ when the direction of loading was parallel to the layers and each layer was heated for 60 seconds. The strength was $49.1 \mathrm{MPa}$ corresponding to 180 seconds of heating. For loading perpendicular to printed layers, the average compressive strength for the two durations of heating was $65.7 \mathrm{MPa}$ and $56.4 \mathrm{MPa}$, respectively. The average shear strength of the printed cubes were $3.8 \mathrm{MPa}(4 \mathrm{MPa})$ and $3 \mathrm{MPa}(3.9 \mathrm{MPa})$ for the two durations of heating, respectively, and when the direction of loading was parallel (perpendicular) to the layers. The average shear strength of the mould-cast cubes was 4.2 MPa.

\section{Acknowledgement}

Authors are grateful to IIT Gandhinagar for the financial support.

\section{References}

[1] B. Khoshnevis, Automated construction by contour crafting: related robotics and information technologies, Automation in Construction 13 (1) (2004) 5-19.

[2] B. Khoshnevis, D. Hwang, K. T. Yao, Z. Yeh, Mega-scale fabrication by contour crafting, International Journal of Industrial and Systems Engineering 1 (3) (2006) 301-320.

[3] R. A. Buswell, R. C. Soar, A. G. Gibb, T. Thorpe, Freeform construction: mega-scale rapid manufacturing for construction, Automation in Construction 16 (2) (2007) 224-231.

[4] S. Lim, R. A. Buswell, T. T. Le, S. A. Austin, A. G. Gibb, T. Thorpe, Developments in constructionscale additive manufacturing processes, Automation in Construction 21 (2012) 262-268.

[5] P. Wu, J. Wang, X. Wang, A critical review of the use of 3-D printing in the construction industry, Automation in Construction 68 (2016) 21-31.

[6] R. Duballet, O. Baverel, J. Dirrenberger, Classification of building systems for concrete 3D printing, Automation in Construction 83 (2017) 247-258.

[7] R. A. Buswell, T. Thorpe, R. C. Soar, A. G. Gibb, Design, data and process issues for mega-scale rapid manufacturing machines used for construction, Automation in Construction 17 (8) (2008) 923-929.

[8] T. T. Le, S. A. Austin, S. Lim, R. A. Buswell, A. G. Gibb, T. Thorpe, Mix design and fresh properties for high-performance printing concrete, Materials and Structures 45 (8) (2012) 12211232. 
[9] A. Kazemian, X. Yuan, E. Cochran, B. Khoshnevis, Cementitious materials for construction-scale 3D printing: Laboratory testing of fresh printing mixture, Construction and Building Materials 145 (2017) 639-647.

[10] T. T. Le, S. A. Austin, S. Lim, R. A. Buswell, R. Law, A. G. Gibb, T. Thorpe, Hardened properties of high-performance printing concrete, Cement and Concrete Research 42 (3) (2012) 558-566.

[11] A. Perrot, D. Rangeard, A. Pierre, Structural built-up of cement-based materials used for 3Dprinting extrusion techniques, Materials and Structures 49 (4) (2016) 1213-1220.

[12] R. Wolfs, F. Bos, T. Salet, Correlation between destructive compression tests and non-destructive ultrasonic measurements on early age 3D printed concrete, Construction and Building Materials 181 (2018) 447-454.

[13] N. Khalil, G. Aouad, K. El Cheikh, S. Rémond, Use of calcium sulfoaluminate cements for setting control of 3D-printing mortars, Construction and Building Materials 157 (2017) 382-391.

[14] A. Rahul, M. Santhanam, H. Meena, Z. Ghani, 3D printable concrete: Mixture design and test methods, Cement and Concrete Composites 97 (2019) 13-23.

[15] B. Panda, M. J. Tan, Experimental study on mix proportion and fresh properties of fly ash based geopolymer for 3D concrete printing, Ceramics International 44 (9) (2018) 10258-10265.

[16] J. G. Sanjayan, B. Nematollahi, M. Xia, T. Marchment, Effect of surface moisture on inter-layer strength of 3D printed concrete, Construction and Building Materials 172 (2018) 468-475.

[17] B. Panda, S. C. Paul, M. J. Tan, Anisotropic mechanical performance of 3D printed fiber reinforced sustainable construction material, Materials Letters 209 (2017) 146-149.

[18] A. Rahul, M. Santhanam, H. Meena, Z. Ghani, Mechanical characterization of 3D printable concrete, Construction and Building Materials 227 (2019) 116710.

[19] C. Gosselin, R. Duballet, P. Roux, N. Gaudillière, J. Dirrenberger, P. Morel, Large-scale 3D printing of ultra-high performance concrete-a new processing route for architects and builders, Materials and Design 100 (2016) 102-109.

[20] M. Hambach, D. Volkmer, Properties of 3D-printed fiber-reinforced Portland cement paste, Cement and Concrete Composites 79 (2017) 62-70.

[21] D. G. Soltan, V. C. Li, A self-reinforced cementitious composite for building-scale 3D printing, Cement and Concrete Composites 90 (2018) 1-13. 
[22] B. Panda, S. C. Paul, L. J. Hui, Y. W. D. Tay, M. J. Tan, Additive manufacturing of geopolymer for sustainable built environment, Journal of Cleaner Production 167 (2017) 281-288.

[23] B. Panda, S. C. Paul, N. A. N. Mohamed, Y. W. D. Tay, M. J. Tan, Measurement of tensile bond strength of 3D printed geopolymer mortar, Measurement 113 (2018) 108-116.

[24] M. Rubio, M. Sonebi, S. Amziane, 3D printing of fibre cement-based materials: fresh and rheological performances, Second International Conference on Bio-Based Building Materials (2017), ClermontFerrand, France.

[25] S. C. Paul, Y. W. D. Tay, B. Panda, M. J. Tan, Fresh and hardened properties of 3D printable cementitious materials for building and construction, Archives of Civil and Mechanical Engineering 18 (1) (2018) 311-319.

[26] R. Wolfs, F. Bos, T. Salet, Hardened properties of 3D printed concrete: The influence of process parameters on interlayer adhesion, Cement and Concrete Research 119 (2019) 132-140.

[27] T. Wangler, E. Lloret, L. Reiter, N. Hack, F. Gramazio, M. Kohler, M. Bernhard, B. Dillenburger, J. Buchli, N. Roussel, et al., Digital concrete: opportunities and challenges, RILEM Technical Letters 1 (2016) 67-75.

[28] B. Zareiyan, B. Khoshnevis, Interlayer adhesion and strength of structures in contour craftingeffects of aggregate size, extrusion rate, and layer thickness, Automation in Construction 81 (2017) $112-121$.

[29] Y. W. D. Tay, G. H. A. Ting, Y. Qian, B. Panda, L. He, M. J. Tan, Time gap effect on bond strength of 3D-printed concrete, Virtual and Physical Prototyping 14 (1) (2019) 104-113.

[30] C. F. Ferraris, Measurement of the rheological properties of high performance concrete: state of the art report, Journal of Research of the National Institute of Standards and Technology 104 (5) (1999) 461.

[31] T. Lecompte, A. Perrot, Non-linear modeling of yield stress increase due to SCC structural build-up at rest, Cement and Concrete Research 92 (2017) 92-97.

[32] L. Reiter, T. Wangler, N. Roussel, R. J. Flatt, The role of early age structural build-up in digital fabrication with concrete, Cement and Concrete Research 112 (2018) 86-95.

[33] D. P. Bentz, S. Z. Jones, I. R. Bentz, M. A. Peltz, Towards the formulation of robust and sustainable cementitious binders for 3D additive construction by extrusion, 3D Concrete Printing Technology 1 (2019) 307-331. 
[34] B. Panda, J. H. Lim, M. J. Tan, Mechanical properties and deformation behaviour of early age concrete in the context of digital construction, Composites Part B: Engineering 165 (2019) 563-571.

[35] P. Rosskopf, F. Linton, R. Peppler, Effect of various accelerating chemical admixtures on setting and strength development of concrete, Journal of Testing and Evaluation 3 (4) (1975) 322-330.

[36] M. Heikal, Effect of calcium formate as an accelerator on the physicochemical and mechanical properties of pozzolanic cement pastes, Cement and Concrete Research 34 (6) (2004) 1051-1056.

[37] H. Justnes, E. C. Nygaard, Technical calcium nitrate as set accelerator for cement at low temperatures, Cement and Concrete Research 25 (8) (1995) 1766-1774.

[38] C. K. Nmai, Cold weather concreting admixtures, Cement and Concrete Composites 20 (2) (1998) 121-128.

[39] J. Péra, J. Ambroise, New applications of calcium sulfoaluminate cement, Cement and Concrete Research 34 (4) (2004) 671-676.

[40] J. Van Der Putten, M. Azima, K. Lesage, G. De Schutter, K. Van Tittelboom, Combination of portland cement and calcium-sulfoaluminate cement: the highroad for durable 3D printing?, RheoCon2 \& SCC9 (2019), Dresden, Germany.

[41] A. M. Neville, J. J. Brooks, Concrete technology, Longman Scientific \& Technical England, 1987.

[42] D. Marchon, S. Kawashima, H. Bessaies-Bey, S. Mantellato, S. Ng, Hydration and rheology control of concrete for digital fabrication: Potential admixtures and cement chemistry, Cement and Concrete Research 112 (2018) 96-110.

[43] L. R. Prudencio Jr, Accelerating admixtures for shotcrete, Cement and Concrete Composites 20 (2) (1998) 213-219.

[44] S. Shekhar, M. Kumar, R. Mathur, Additive manufacturing using self-compacting concrete, Indian Patent Application No.: 201821026589 (July 17, 2018).

[45] M. Banzi, M. Shiloh, Getting started with Arduino: the open source electronics prototyping platform, Maker Media, Inc., 2014.

[46] S. Shekhar, R. Mathur, 3D printing of self-compacting concrete, First International Conference on 3D Construction Printing (2018), Melbourne, Australia.

[47] H. Flaig, Bipolar stepping motor, US Patent 4,141,210 (Feb. 27 , 1979).

[48] A. O'Dwyer, Handbook of PI and PID controller tuning rules, Imperial College Press, 2009. 
[49] D. Decoster, J. Harari, Optoelectronic sensors, John Wiley \& Sons, 2013.

[50] P. C. Aïtcin, High performance concrete, CRC press, 2011.

[51] Bureau of Indian Standards (BIS), Specification for 53-grade ordinary Portland cement, IS 12269 (2013), Bureau of Indian Standards, New Delhi.

[52] American Society for Testing and Materials (ASTM), Standard specification for chemical admixtures for concrete, ASTM C494 (1999), American Society for Testing and Materials, West Conshohocken, PA.

[53] American Society for Testing and Materials (ASTM), Standard specification for flow table for use in tests of hydraulic cement, ASTM C230/C230M-14 (2014), American Society for Testing and Materials, West Conshohocken, PA.

[54] N. Roussel, C. Stéfani, R. Leroy, From mini-cone test to abrams cone test: measurement of cementbased materials yield stress using slump tests, Cement and Concrete Research 35 (5) (2005) 817-822.

[55] Bureau of Indian Standards (BIS), Specification for vicat apparatus, IS 5513 (1996), Bureau of Indian Standards, New Delhi.

[56] D. Lootens, P. Jousset, L. Martinie, N. Roussel, R. Flatt, Yield stress during setting of cement pastes from penetration tests, Cement and Concrete Research 39 (5) (2009) 401-408.

[57] Bureau of Indian Standards (BIS), Methods of test for soils, Part 10: Determination of unconfined compressive strength, IS 2720-10 (1991), Bureau of Indian Standards, New Delhi.

[58] N. Roussel, A thixotropy model for fresh fluid concretes: theory, validation and applications, Cement and Concrete Research 36 (10) (2006) 1797-1806.

[59] American Society for Testing and Materials (ASTM), Standard test method for shear testing of aluminum alloys, ASTM B769 -11 (2016), American Society for Testing and Materials, West Conshohocken, PA.

[60] Bureau of Indian Standards (BIS), Plain and reinforced concrete - code of practice, IS 456 (2000), Bureau of Indian Standards, New Delhi.

[61] Bureau of Indian Standards (BIS), Method of tests for strength of concrete, IS 516 (1959), Bureau of Indian Standards, New Delhi. 